\title{
ENCUESTA CHECA SOBRE VIDA UTIL DE ESTRUCTURAS
}

404-1

Bajo la dirección del doctor Milik TICHY, presidente de la delegación de Checoslovaquia en el CEB, el Instituto de Investigaciones de la Edificación, de la Universidad Técnica de Praga, ha llevado a cabo recientemente una encuesta en dicho país relativa a la vida útil de las estructuras, aspecto éste del que existen pocos datos en la literatura especializada y que cada día resulta más necesario esclarecer, dada su influencia en cualquier problema de fiabilidad y garantía de calidad.

Por su interés, reproducimos a continuación un resumen del planteamiento de la encuesta y del resultado de la misma.

\section{Población encuestada}

Cuarenta y seis ingenieros altamente cualificados en diversas áreas (profesores, investigadores, proyectistas, constructores, etcétera).

Cada uno recibió seis hojas en las que se aludía a 78 tipos diferentes de edificios y estructuras de obra civil.

\section{Opiniones pedidas}

Expresar la magnitud de las siguientes cantidades:

a) Vida útil técnica estimada: tiempo al cabo del cual los costes de mantenimiento superan un límite aceptable, por lo que la estructura debería ser demolida.

b) Vida útil funcional estimada: tiempo al cabo del cual la estructura no cubre las necesidades reales, por lo que resultaría ventajoso sustituirla por otra nueva.

c) Vida útil efectiva: según experiencia de cada encuestado. d) Tiempo hasta la primera reparación general.

e) Vida útil de estructuras de carácter temporal, sin añadir datos acerca del tipo de objetos involucrados.

f) Plazo a partir del cual una construcción puede ser considerada como monumento técnico o histórico.

Se pidió a los encuestados que sólo respondiesen a los casos que conocían bien. Por ello, el número de respuestas recibidas para cada caso varió entre 3 y 15 , siendo 30 el número total de encuestados que respondieron.

En la Tabla de la página siguiente se ofrecen los resultados expresados en años, para algunos tipos estructurales.

En cuanto a la vida útil de estructuras de carácter temporal, las respuestas oscilaron entre un año $\mathbf{y}$ doscientos años, con valor medio de 31 años.

Respecto al plazo para ser considerada monumento una construcción, las respuestas oscilaron entre 40 años y 250 años, con valor medio de 109 años.

Si algún lector está interesado en más detalles, o desea aportar sus opiniones y sugerencias, puede escribir directamente a:

\section{Dr. Milík Tichý}

Building Research Institute

Technical University in Prague

Solínova 7

16608 Praha 6

Información elaborada por A.G. Meseguer 


\begin{tabular}{|c|c|c|c|c|c|}
\hline \multirow{2}{*}{$\begin{array}{l}\text { TIPO DE } \\
\text { CONSTRUCCION }\end{array}$} & \multirow{2}{*}{ MATERIAL } & \multicolumn{2}{|c|}{ VIDA UTLL ESTIMADA } & \multirow{2}{*}{$\begin{array}{l}\text { VIDA UTIL } \\
\text { EFECTIVA }\end{array}$} & \multirow{2}{*}{$\begin{array}{l}\text { TIEMPO PARA } \\
\text { LA PRIMERA } \\
\text { REPARACION }\end{array}$} \\
\hline & & TECNICA & FUNCIONAL & & \\
\hline \multirow{4}{*}{$\begin{array}{l}\text { EDIFICIOS } \\
\text { DE } \\
\text { VIVIENDAS }\end{array}$} & LADRILLO & $70-200(112)$ & $30-100(60)$ & $90-500(148)$ & $20-75(32)$ \\
\hline & ENTRAMADOS DE HORMIGON & $60-250(115)$ & $30-150(66)$ & $80-200(120)$ & $20-75(40)$ \\
\hline & PANELES DE HORMIGON & $50-140(96)$ & $30-120(53)$ & $80-90(86)$ & $20-50(34)$ \\
\hline & ACERO & $50-150(76)$ & $20-150(50)$ & $20-150(88)$ & $15-100(40)$ \\
\hline CHALETS & - & $20-200(55)$ & $20-50(32)$ & $30-70(49)$ & $10-40(20)$ \\
\hline \multirow{2}{*}{$\begin{array}{c}\text { EDIFICIOS } \\
\text { INDUSTRIALES }\end{array}$} & HORMIGON & $50-200(88)$ & $20-120(46)$ & $50-120(80)$ & $15-150(38)$ \\
\hline & ACERO & $30-100(61)$ & $10-80 \quad(33)$ & $30-120(65)$ & $10-30(16)$ \\
\hline \multirow{2}{*}{$\begin{array}{l}\text { PUENTES DE } \\
\text { AUTOPISTA }\end{array}$} & HORMIGON & $50-200(108)$ & $15-100 \quad(54)$ & $20-150(93)$ & $15-30(24)$ \\
\hline & ACERO & $60-120(81)$ & $15-80(39)$ & $30-120(80)$ & $10-50(24)$ \\
\hline \multirow{2}{*}{ PRESAS } & HORMIGON & $100-500(258)$ & $80-500(295)$ & $100-500(234)$ & $25-200(109)$ \\
\hline & TIERRA & $70-500(217)$ & $50-500(202)$ & $80-500(202)$ & $25-100(59)$ \\
\hline \multirow{2}{*}{ SILOS } & HORMIGON & $60-150(102)$ & $50-150(78)$ & $50-100(78)$ & $30-50(40)$ \\
\hline & ACERO & $50-60(52)$ & $15-150(73)$ & $35-50(42)$ & $25-25(25)$ \\
\hline DEPOSITOS DE AGUA & HORMIGON & $30-120(84)$ & $30-80(68)$ & $30-60(73)$ & $15-60(35)$ \\
\hline \multirow{3}{*}{$\begin{array}{c}\text { CHIMENEAS } \\
\text { ALTAS }\end{array}$} & LADRILLO & $30-150(85)$ & $30-150(80)$ & $20-200(113)$ & $10-150(41)$ \\
\hline & HORMIGON & $30-200(92)$ & $30-150(66)$ & $20-200(101)$ & $10-50(25)$ \\
\hline & ACERO & $20-50(31)$ & $15-150(47)$ & $30-50(35)$ & $10-25(13)$ \\
\hline \multirow{2}{*}{$\begin{array}{c}\text { TORRES DE } \\
\text { REFRIGERACION }\end{array}$} & HORMIGON & $50-60(57)$ & $30-35(32)$ & $15-40(28)$ & $30-30(30)$ \\
\hline & ACERO & $25-50(34)$ & $25-25(25)$ & $12-30(19)$ & $15-25(22)$ \\
\hline \multirow{2}{*}{$\begin{array}{c}\text { TORRES DE } \\
\text { TV }\end{array}$} & HORMIGON & $80-100(93)$ & $20-80(43)$ & $30-40(37)$ & $10-20(15)$ \\
\hline & ACERO & $30-50(42)$ & $15-30(22)$ & $30-50(40)$ & $10-25(15)$ \\
\hline
\end{tabular}

NOTA : Las dos primeros cifras indicon las respuestos extremas. La cifro entre parentesis corresponde al valor medio.

\section{publicación del i.e.t.c.c.}

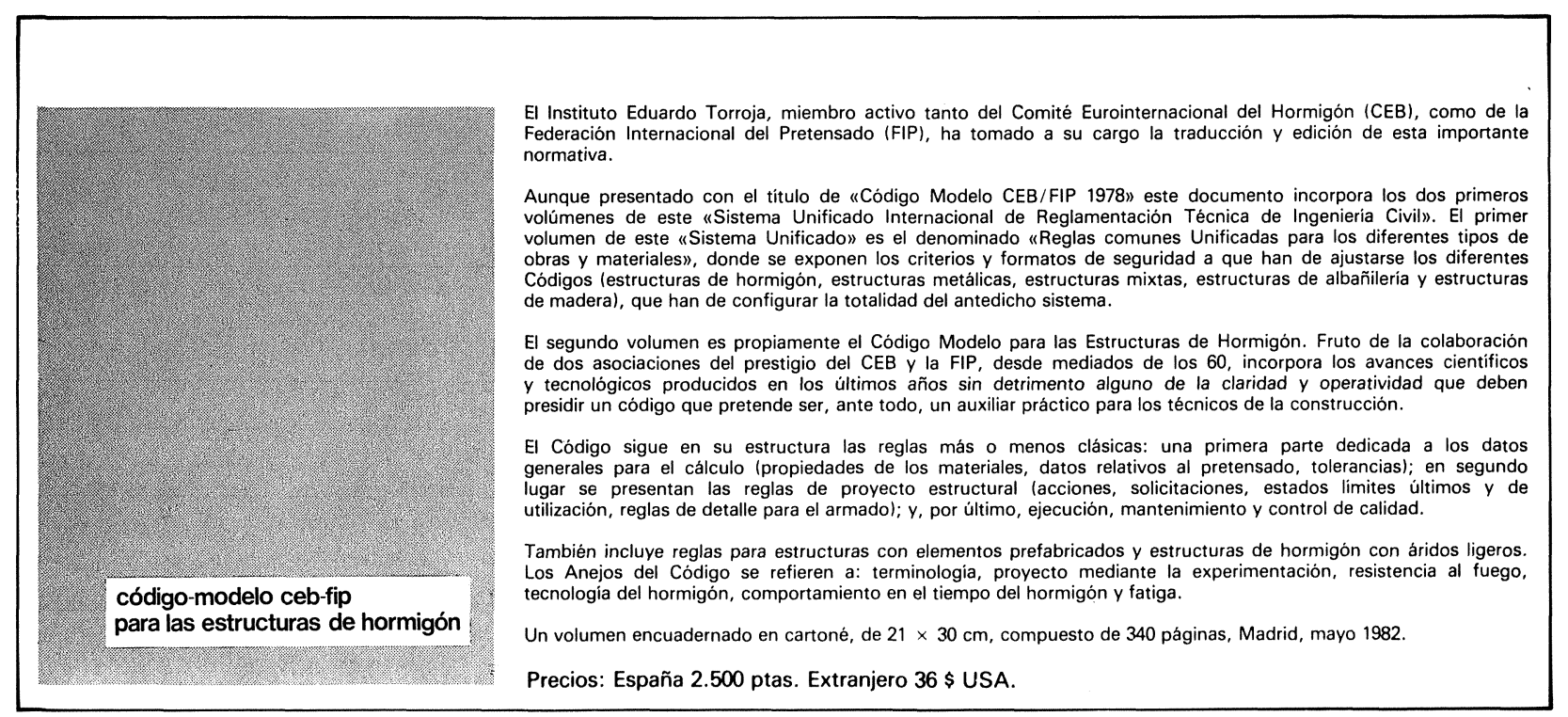

